\title{
RELATIONSHIP BETWEEN PHYSIOLOGICAL INDICATORS OF OAT AND METEOROLOGICAL FACTORS IN TIBET'S ALPINE PASTORAL AREAS
}

\author{
TANG, P. C. ${ }^{1,2,3}-\mathrm{XU}, \mathrm{B}^{{ }^{3}}{ }^{*}-\mathrm{GAO}, \mathrm{Z} . \mathrm{Y}^{1,2}-\mathrm{LI}, \mathrm{H} . \mathrm{P}^{3}{ }^{3}-\mathrm{XU}, \mathrm{Y}^{4}-\mathrm{HE}, \mathrm{M}^{4}$ \\ ${ }^{1}$ State Key Laboratory of Simulation and Regulation of Water Cycle in River Basin \\ No. 1 Fuxing Road, 100038 Beijing, PR China \\ ${ }^{2}$ China Institute of Water Resources and Hydropower Research (IWHR) \\ No. 1 Fuxing Road, 100038 Beijing, PR China \\ ${ }^{3}$ Institute of Water Resources for Pastoral Area of IWHR \\ No. 128 Daxue East Road, Saihan, 010020 Hohhot, PR China \\ ${ }^{4}$ Hebei Institute of Water Resources \\ No. 310 Taihua Road, 050000 Shijiazhuang, PR China \\ *Corresponding author \\ e-mail:543077207@qq.com; phone: +86-188-4717-1366 \\ (Received $2^{\text {nd }}$ Feb 2018; accepted $3^{\text {rd }}$ May 2018)
}

\begin{abstract}
According to large daily temperature difference, strong solar radiation and significant change of air humidity in the alpine area of Tibet, a field experiment was conducted to analyze the oat's diurnal variation of the leaf water potential $\left(\psi_{L}\right)$, transpiration rate $(T r)$ and net photosynthetic rate $(P n)$. Meanwhile, the relationship between oat's physiological indicators and typical meteorological factors (atmospheric temperature $(T)$, solar radiation $\left(R_{s}\right)$, relative air humidity $(R H)$ ) were investigated with regression models. Results showed that the oat's daily change curve of $\psi_{L}$ showed 'V-type' in the seeding and heading stages and 'W-type' in the jointing and tillering stages. As shown in the results, oat's $P n$ presented a decreasing tendency in a day and the peak appearing between 9:00 and 10:00 at one day in each growing stage. The $\operatorname{Tr}$ presented double-peak curves and midday depression in the seeding and heading stages. The variation tendency about oat's $T r$ in the tillering stage and jointing stage was "Multipeak" type without distinct midday depression and parabolic tendency. By multiple regression analysis between the data of oat's physiological indexes and comprehensive factors, the $\psi_{L}, \operatorname{Tr}$ and $P n$ of oat in alpine region can be predicted under condition of adequate water supply.
\end{abstract}

Keywords: oat, leaf water potential, transpiration rate, net photosynthetic rate, meteorological factor, high-altitude area

\section{Introduction}

In recent years, with the development of pasture land water conservancy, the study of artificial grass water requirement and irrigation program is a public concern. Then the moisture physiological characteristics of pasture are of special note. For example, Liu et al. (2009) studied the effect of soil water stress on osmoregulation substance content of oat leaf. However, the relationship between leaf water potential $\left(\Psi_{L}\right)$, transpiration rate $(T r)$, photosynthetic rate $(P n)$, which are the important parameters in the water cycle processes and meteorological factors are rarely investigated.

The leaf water potential is a basic indicator to reveal the status of crop water. The change of leaf water potential depends on many requirements of soil-plant-atmosphere continuum and complex interaction among the regions of plant. The daily variation rule of leaf water potential about winter wheat in the filling stage under the condition of 
sprinkling irrigation and surface irrigation were investigated by Yao et al. (2009). It found that the leaf water potential of winter wheat irrigated by sprinkling irrigation was higher than that by surface irrigation. Due to the individual and environmental variations, the leaf water potential of different plants will be different. The value of leaf water potential is associated closely with its yield, which is also varied with environmental factors. Kang et al. (1994) found that the $\Psi_{L}$ of winter wheat will decrease with crop growing. Fu et al (2012) showed that the soil moisture content and temperature were the main factors for the leaf water potential change of Phragmites in arid areas. However, the relationship between leaf water potential of oat and meteorological indexes is remains unclear.

Transpiration regulates the water balance in plants and is influenced indirectly by environmental factors through effects on stomatal opening (Tamang and Sadok, 2018). Liu et al. (2003) studied the transpiration diurnal characteristics of spring wheat and found that the solar radiation and temperature will affect transpiration obviously. Peng et al. (2005) considered that the reduction of soil water content would put off the diurnal maximum of transpiration of late rice. His study also showed that there were different effects degree of vapor pressure deficit and stomatal conductance on transpiration of late rice in the different growth stages. Evapotranspiration and stomatal conductance are known to decrease as leaves age increasing in many species (Sobrado et al., 1994). Meanwhile, stomatal conductance for transfer of water vapor from the interior of the leaf to the atmosphere is affected by irradiance, leaf age, temperature, leaf water status, and the difference in absolute humidity between ambient air and the interior of the leaf (Wardlaw et al., 1967; Johnsonet al., 1983; Ku et al., 1977; Li and Zhou, 2004; Zhao et al., 2011). Some studies found that there was significantly correlational relationship between stomatal conductance and temperature, humidity and leaf water potential. At present, the model about relationship between stomatal conductance and environmental factors is composed of two classes. One is empirical model, such as Jarvis, Ball and so on (Ball et al., 1987; Jarvis et al., 1976; Leuning, 1995). Others are the optimization theory of stomatal regulation proposed by Cowan and Farquhar (1977) and optimization model of stomatal conductance established by Medlyn et al. (2011).

The diurnal variation of plant photosynthesis is not only the basic unit of material accumulation and physiological metabolism in the plant's production process but also an important method to analyze the impact of environment on plant growth and metabolism. Under normal circumstances, the daily change curve of plant photosynthesis is a bimodal type or unimodal type. Yu et al. (2015) reported that the diurnal variation of net photosynthesis of maize presenting the bimodal curve with apparent photosynthetic "noon break" phenomenon. The diurnal variation of plant photosynthesis is different from the separate plant species and the surrounding environment change (Farquhar and Sharkey, 1982). Many environmental factors will affect the plant photosynthesis, such as Photon flux density, temperature, relative humidity and so on. Under natural conditions, the influence of environmental factors on plant photosynthesis is the result of combination. However, there is hardly any research on the impact of meteorological indexes on oat photosynthesis is rarely.

The objectives of this research are:

(1)To investigate the daily variation of oat's $\Psi_{L}, P n$ and $T r$ in different growth stages on the condition of full irrigation in plateau area.

(2)To determine the relationships between oat's physiological indexes and meteorological factors in plateau area. 


\section{Materials and methods}

\section{Experimental site}

Tibet, which is mainly located in Qinghai-Xizang Plateau, is in the average elevation of $4000 \mathrm{~m}$. There are 820 million ha natural grasslands in the alpine area of Tibet and the meteorological characteristics are large daily temperature difference, strong solar radiation and significant change of air humidity in this area. The problems of uneven distribution of water-heat resource in space-time and soil depletion are severe in the northern of Tibet plateau region especially. The special physiographic factors and production custom make the grass irrigation technology lagged far behind.

Field experiments were conducted in the central Tibet with longitude $90^{\circ} 45^{\prime}-91^{\circ} 31^{\prime}$ and north latitude $29^{\circ} 31^{\prime}-31^{\circ} 04^{\prime}$ in the Damxung County in Lasa (Fig. 1). The region with an average altitude of $4200 \mathrm{~m}$ is plateau-continental climate and the rainy season and dry season are clear. The annual mean precipitation is $480 \mathrm{~mm}$ and the rain mainly fall between June and September. In the region, with multi-year average evaporation being $1966 \mathrm{~mm}$, the frost-free period is only 60 days and percentage of sunshine is above $60 \%$ in a year. The study area has adequate solar resource but is lack of hot resource. Table 1 presents information on the physical properties of the soil in the field area. Surface soil above $40 \mathrm{~cm}$ mainly consists of loam, while the lower layer mainly consists of silver sand and rubble.

Table 1. Physical properties of the soil in the field area

\begin{tabular}{c|c|c|c|c|c|c}
\hline $\begin{array}{c}\text { Soil horizon } \\
(\mathbf{c m})\end{array}$ & $\begin{array}{c}\text { Field capacity } \\
(\boldsymbol{\%})\end{array}$ & $\begin{array}{c}\text { Soil bulk density } \\
\left(\mathbf{g} / \mathbf{c m}^{\mathbf{3}}\right)\end{array}$ & $\begin{array}{c}\text { Percent clay } \\
(\boldsymbol{\%})\end{array}$ & $\begin{array}{c}\text { Percent loam } \\
(\boldsymbol{\%})\end{array}$ & $\begin{array}{c}\text { Percent sand } \\
(\boldsymbol{\%})\end{array}$ & $\begin{array}{c}\text { Soil } \\
\text { texture }\end{array}$ \\
\hline $0-10$ & 17.96 & 1.48 & 7.8 & 44.07 & 48.13 & Loam \\
$10-20$ & 16.14 & 1.59 & 7.66 & 43.48 & 48.85 & Loam \\
$20-30$ & 18.03 & 1.55 & 7.51 & 42.8 & 49.69 & Loam \\
$30-40$ & 18.28 & 1.56 & 8.08 & 47.11 & 44.81 & Loam \\
\hline
\end{tabular}

Note: Soil texture classification according to the quality standard of America

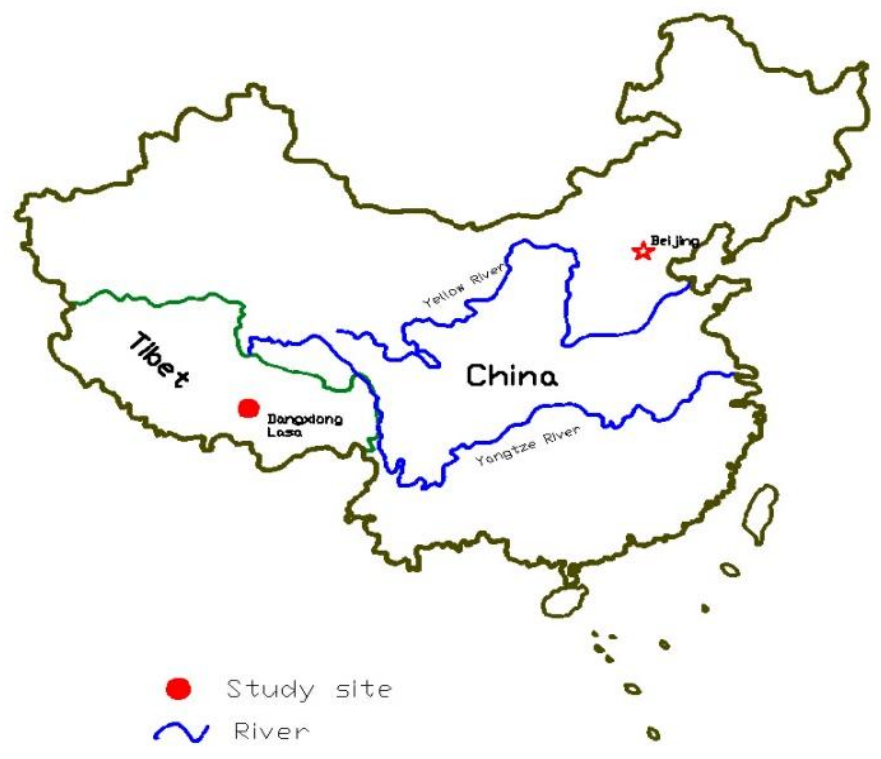

Figure 1. The location of study site 


\section{Agronomy}

The experimental design was a randomized complete block with 3 replications. Each experimental plot was $12 \mathrm{~m}$ long by $5 \mathrm{~m}$ wide $\left(60 \mathrm{~m}^{2}\right)$ with $30 \mathrm{~cm}$ height ridge. A buffer zone spacing of $2.00 \mathrm{~m}$ was provided between the plots. The oat (Danmai 444) was used for the experiment and planted on June $15^{\text {th }}$ in 2013 . The sowing rate was $187.5 \mathrm{~kg} / \mathrm{ha}$ and the planting method was strip seeding with line spacing of $25 \mathrm{~cm}$. Before planting, $4.5 \mathrm{t} / \mathrm{ha}$ organic fertilizer and $224.9 \mathrm{~kg} / \mathrm{ha} \mathrm{N}$ (as ammonium nitrate) were fertilized. One and half months after planting, a further $74.96 \mathrm{~kg} / \mathrm{ha}$ of $\mathrm{N}$ (as ammonium nitrate) was applied. Crops were manually harvested when ripe rate reached about $95 \%$ (early September). Soil moisture was measured once every 7 days using TDR and validated by soil samples using soil drilling. The experiment was carried out without water stress. When the soil moisture was lower than the lower irrigation limit $\left(\mathrm{W}_{\mathrm{cg}}\right)$, the irrigation would be carried out with ground irrigation. The detailed growing period information of oat and lower irrigation limit are shown in Table 2.

Table 2. Growing period of oat and lower irrigation limit

\begin{tabular}{c|c|c|c|c|c}
\hline \multirow{2}{*}{$\begin{array}{c}\text { Growth } \\
\text { period }\end{array}$} & \multicolumn{2}{|c|}{ Seeding stage } & Tillering stage & Jointing stage & Heading stage \\
\cline { 2 - 4 } & Pre-emergence & After emergence & Larly July- & $\begin{array}{c}\text { Late July- middle } \\
\text { of August }\end{array}$ & $\begin{array}{c}\text { Late August- } \\
\text { harvest }\end{array}$ \\
$\mathrm{P}_{\mathrm{g}}$ & $\begin{array}{c}\text { Early June-late } \\
\text { June }\end{array}$ & $\begin{array}{c}\text { Late June-early } \\
\text { July }\end{array}$ & $\begin{array}{c}\text { Earld of July } \\
\text { middle }\end{array}$ & $75(\%) \mathrm{FC}$ & $70(\%) \mathrm{FC}$ \\
\hline
\end{tabular}

Notes: (a) Each stage water condition refers to the percentage of maximum field capacity (FC); $\mathrm{W}_{\mathrm{cg}}$ : Lower irrigation limit in different growth period with full irrigation (b) $\mathrm{P}_{\mathrm{g}}$ : The beginning and ending of growth period

\section{Meteorological factors}

Due to the large daily temperature difference, strong solar radiation and significant change of air humidity, in the research district, we selected the $T, R_{s}$ and $R H$ as the typical meteorological factors. The data of $R H$ and $T$ were measured by the meteorological station in farmland of Damxung and $R_{s}$ was calculated from the Equations 1 and 2 (Allen et al., 1998).

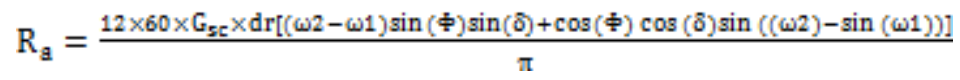

$$
\begin{aligned}
& R_{s}=\left(0.25+0.5 \times \frac{n}{N}\right) \times R_{a}
\end{aligned}
$$

where $R_{a}$ is extraterrestrial radiation, $\mathrm{MJm}^{-2} \mathrm{~h}^{-1} ; R_{s}$ is solar radiation, $\mathrm{MJm}^{-2} \mathrm{~h}^{-1} ; G_{s c}$ is solar constant, $0.082 ; d r$ is the reciprocal of relative distance between the sun and earth; $\delta$ is the solar declination; $\Phi$ is the geographical latitude; $\omega 1(\omega 2)$ is the solar hour angle in the early (late) period and $\mathrm{n} / \mathrm{N}$ is the relative sunshine duration.

\section{Measurements}

Oat blade with well growth, normal color and size (second leave from the top of plant in seedling stage and third leave from the top of plant in tillering stage, jointing 
stage and heading stage) were selected to monitor the leaf water potential $\left(\psi_{L}, \mathrm{MPa}\right)$ with 3 plants replication using the water dew point meter (Psypro, Wescor Inc in USA) every one hour. Oat blades with well growth and normal color and size were selected to monitor the transpiration rate $\left(T r\right.$, millimol $\left.\bullet \mathrm{m}^{-2} \mathrm{~s}^{-1}\right)$ and net photosynthetic rate $\left(P n, \mu \mathrm{mol} \cdot \mathrm{m}^{-2} \mathrm{~s}^{-1}\right)$ using automatic portable photosynthesis system (LCPro-SD, ADC in British) every $1 \mathrm{~h}$ with 3 plants replication. The meteorological characteristics of measurement's days are better sunshine, gentle breeze and no rainfall. The $\psi_{L}$ was measured for one day in seeding, tillering and heading stage, and measured for 6 days at jointing stage. The $T r$ and net $P n$ were measured for one day in seeding, tillering, jointing and heading stage, respectively.

\section{Data analysis}

The data were subjected to the analysis of regression for meteorological factors and crop physiological indexes using SPSS software. The significance of regression model was determined with an F test. The F-protected least significance difference (LSD) was calculated at the 0.05 and 0.01 probability level, respectively.

\section{Results and discussion}

Daily variation of oat's leaf water potential, net photosynthetic rate and transpiration rate at different growth stages

Daily variation of oat's leaf water potential in different growth stages

Under conditions of full irrigation, ample sunshine and suitable temperature, diurnal variation of $\psi_{L}$ in different growth stages were selected to contrast (Fig. 2). According to the data, the diurnal $\psi_{\mathrm{L}}$ in growth periods ranged largely with maximum of $6 \mathrm{MPa}$ under the special environment of high altitude, strong radiation and large diurnal temperature range in Tibet. However, the $\psi_{L}$ of winter wheat's variation value was only $3 \mathrm{Mpa}$ and the $\psi_{L}$ of Mongolian blue-beard grew in the alpine region is only $1.24 \mathrm{Mpa}$ (Han et al., 2008; Tong et al., 2005).

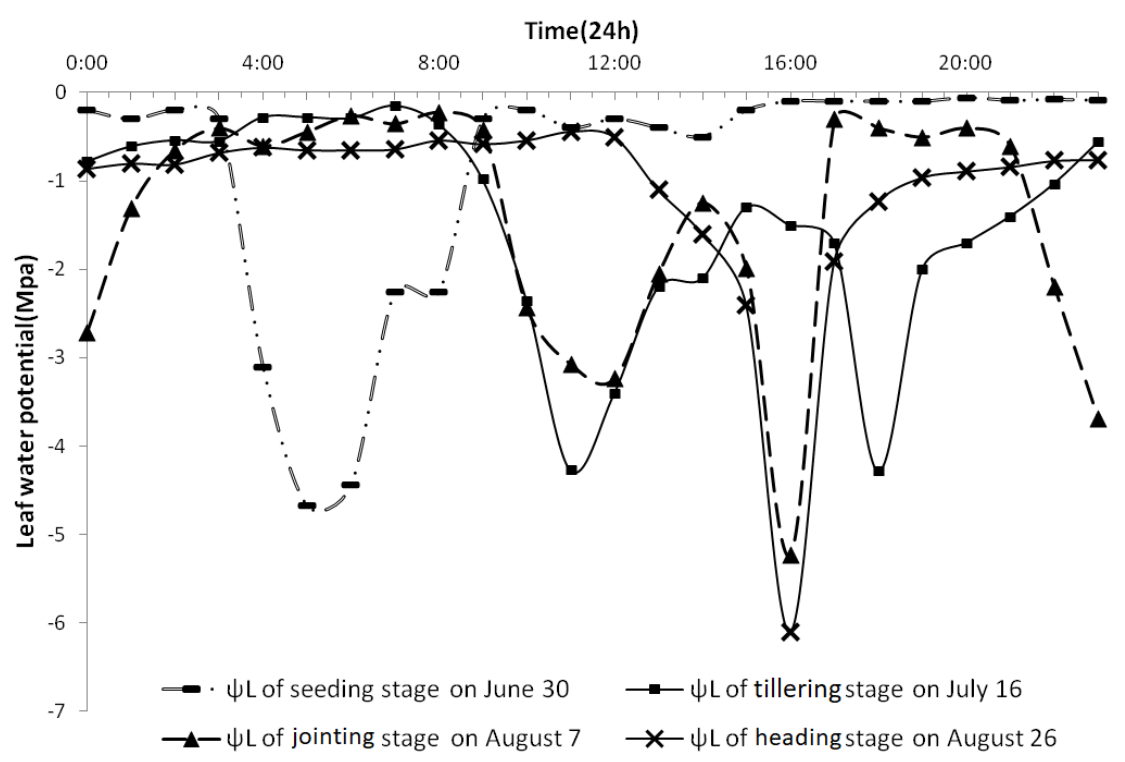

Figure 2. Daily variation of $\psi_{L}$ under different growing periods 
In the seedling stage, the $\psi_{L}$ usually changed at night and the minimum of $-4.67 \mathrm{MPa}$ appeared at day break, and the change trend showed "V-type". The trough of $\psi_{L}$ happened five hours before sunrise, when $T$ and $R_{S}$ were lower with the $R H$ being larger. The $\psi_{L}$ would reach the larger value in the day time. This is due to cells of seedling leaf avoiding to be damaged by radiation or avoiding the effect of water stress on crops by excessive transpiration. The frequent fluctuations of $\psi_{L}$ at dawn reflected the frequent water exchange with external and stronger life activity in the seedling stage of oat. This indicates that the oat could adapt to the low temperature at night in the seedling stage. In contrast, high temperature and radiation will inhibit the growth of oat in the seedling stage, which is related to the undeveloped oat root and immature mechanism of stomata cell for opening and closing.

(2) In the tillering stage, the oat grew quickly and exchange moisture with external environment frequently. The $\psi_{L}$ fluctuated significantly at daytime and the trend showed "W-type". The lowest trough of $\psi_{L}$ appeared at the 10:00 to 11:00 with a minimum value of $-4.27 \mathrm{MPa}$ and 18:00 with a minimum value of $-4.28 \mathrm{MPa}$ (Fig. 1). With the rise of $R_{s}$ and $T$, the oat reduced their own tissue water potential to absorb more moisture for the life activity. The $\psi_{L}$ decreased after sunrise. The temperature reached the maximum at noon. Through regulating the stomata opening and closing, the oat reduced water loss. Then as the sun set, the $T$ fell, $\psi_{L}$ reduced again to absorb more moisture. The $\psi_{L}$ returned to a higher value of $-1.7 \mathrm{MPa}$ at 21:00. The results support the conclusions of Guo, et al. (2006) and Tong et al. (2005) that the trend of $\psi_{L}$ showed "W-type" on the condition of full-irrigation. The oat had already certain adaptability to the change on meteorological factors in the tillering stage. The life activity at daytime was going to be vigorous than it at night.

(3) The jointing stage is the critical period for the organic synthesis and accumulation of plant (Tian et al., 2012). The diurnal variation of $\psi_{L}$ tended to be stable and the trends were similar to that in the tillering stage with two troughs. The time when the first trough appeared at 11:00 was consistent with the moment of tillering stage's first trough; however, the second trough was about two hours upfront than that in tillering stage with a minimum value of $-5.22 \mathrm{Mpa}$. This phenomenon can be attributed to the special meteorological conditions. The general trend of $\psi_{L}$ was higher in the morning and evening and the $\psi_{L}$ was significantly reduced with great fluctuations. At 14:00, the $\psi_{L}$ was at a high value of $-1.24 \mathrm{MPa}$, when the oat's stomatal conductance decreased rapidly, guard cell shrinkage and partial stomata closure in response to intense light and drying air. Therefore through short "nap", the oat could adapte the change of weather factor and control water balance of the body (Kang et al., 1991).

(4) In heading stage, the reproductive growth replaced the vegetative growth gradually. The $\psi_{L}$ maintaining a relatively high value tended to "V-model" with a minimum of $-6.1 \mathrm{MPa}$ at 16:00 (Fig. 1). The occurrence time of trough agree with the moment of the second trough appeared in tillering and jointing stages. The results are keeping with the conclusions of Guo et al. (2006) that the trend of $\psi_{L}$ showed "V-type". This proved that water currently had strong driving force to promote water from soil to root at 16:00-18:00 under non-water stress condition. To some extent, it indicates that the heading stage is the critical period to translate the energy to organics and so the lack of water will affect the quality of artificial grassland. However, further study is needed to confirm why the $\psi_{L}$ with a minimum of $-6.1 \mathrm{Mpa}$ at high altitudes lower than other areas obviously. 


\section{Daily variation of net photosynthetic rate of oat in different growth stages}

In low elevation regions, previous studies suggested that the curves of diurnal variation on $P n$ of gramineous plants presented double-peak, and an obvious midday depression at 12:00 o'clock (Li et al., 2013; Liu et al., 2006). This study showed that $P n$ has its unique change rule at high altitudes. The daily variation patterns of $P n$ of oat are presented in Figure 2. As the trend lines implied in Figure 3, it presented a decreasing tendency in a day. The variation tendency of oat's $P n$ were basic consistent without fixed peaks and troughs model in different growth stages. The $P n$ on the morning was higher than that on the afternoon and the peak appeared between 9:00 and 10:00 at one day. After the peak value appeared, there would be a reduction and the downturn would last a long time in the tillering stage and heading stage. The maximum of $P n$ in the seeding stage, tillering stage, jointing stage and heading stage were $10.56 \mu \mathrm{mol} \mathrm{m}^{-2} \mathrm{~s}^{-1}$, $9.91 \mu \mathrm{mol} \mathrm{m} \mathrm{s}^{-1}, 10.01 \mu \mathrm{mol} \mathrm{m} \mathrm{s}^{-1}$ and $9.01 \mu \mathrm{mol} \mathrm{m} \mathrm{s}^{-1}$, respectively.

At 12:00 am and 4:00 pm, an obvious valley appeared in the seeding stage; likewise the valley appeared on the morning and afternoon in the jointing stage, while the minimum values of $P_{n}$ were $5.1 \mu \mathrm{mol} \mathrm{m} \mathrm{m}^{-1}$ and $5.4 \mu \mathrm{mol} \mathrm{m} \mathrm{m}^{-2} \mathrm{~s}^{-1}$, respectively. The $P n$ in tillering stage witnessed significant downturn at 12:00-14:00, which was similar to the $P n$ in heading stage at 11:00-14:00, troughs appeared with the minimum value of $5.2 \mu \mathrm{mol} \mathrm{m} \mathrm{m}^{-2}$ and $4.4 \mu \mathrm{mol} \mathrm{m} \mathrm{s}^{-1}$, respectively.
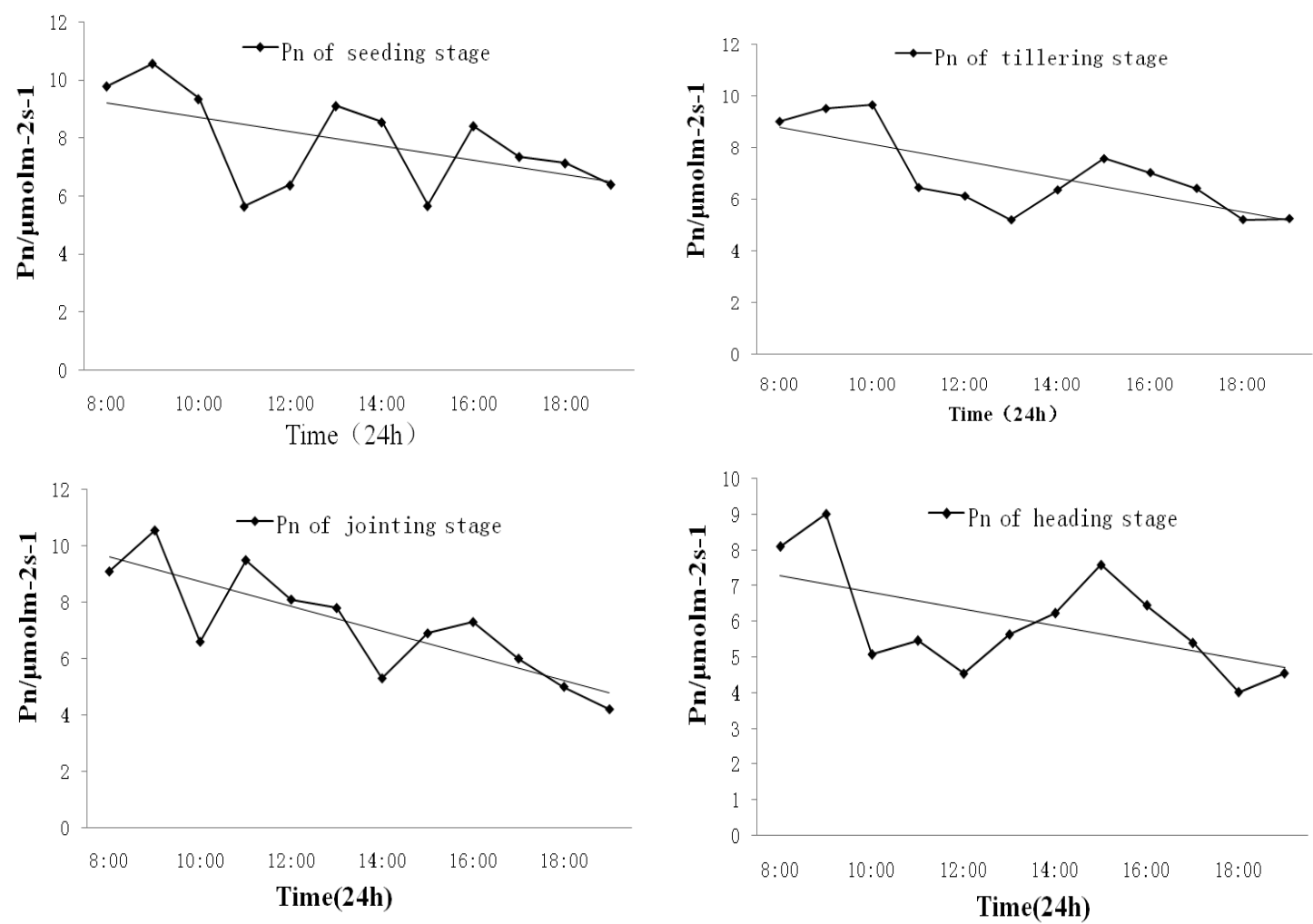

Figure 3. Daily variation of Pn under different growing periods

\section{Daily variation of oat's transpiration rate at different growth stages}

The $\operatorname{Tr}$ of oat in the seeding stage is obviously less than that in the tillering stage, jointing stage and heading stage (Fig. 4). 
(1) The $\operatorname{Tr}$ presents double-peak curves and midday depression in the seeding and heading stage

The obvious tendency of bimodal patterns about $\operatorname{Tr}$ are appeared in the seeding stage and heading stage of oat. This changing trend is similar to the result reported by Luo et al. (2011), the curves of diurnal variation in $\operatorname{Tr}$ of Medicago sativa had two peaks and an obvious midday depression with or without water stress at lower altitude. At 12:00, the $T r$ in the seeding stage peaks at the maximum of 45.3 millimol $\cdot \mathrm{m}^{-2} \mathrm{~s}^{-1}$, while the midday depression appearing from 13:00 to 16:00. The $\operatorname{Tr}$ value is the minimum of one day with being 15.2 millimol $\bullet \mathrm{m}^{-2} \mathrm{~s}^{-1}$ at $8: 00$ in the morning. In heading stage, the maximum value $\left(64.5 \mathrm{millimol} \cdot \mathrm{m}^{-2} \mathrm{~s}^{-1}\right)$ of $\operatorname{Tr}$ appeared at 11:00 and the minimum value (13.7 millimol $\left.\cdot \mathrm{m}^{-2} \mathrm{~s}^{-1}\right)$ of $\operatorname{Tr}$ appeared at 20:00. The curves of diurnal variation in $\operatorname{Tr}$ had an obvious midday depression between 12:00 and 14:00.

(2) The $\operatorname{Tr}$ presents "Multi-peak" type in the tillering stage and jointing stage

Different from the current research about grass, the variation tendency on $\operatorname{Tr}$ of oat in the tillering stage and jointing stage was "Multi-peak" type without distinct midday depression and parabolic tendency. In tillering stage, the $T r$ would rise rapidly after sunrise and reach to the first summit $\left(66.1 \mathrm{millimol} \cdot \mathrm{m}^{-2} \mathrm{~s}^{-1}\right)$ at 11:00, and there were more peak values which appeared at 14:00 and 17:00 respectively in one day. In jointing stage, the $\operatorname{Tr}$ reached to the first peak $\left(73.8\right.$ millimol $\left.\bullet \mathrm{m}^{-2} \mathrm{~s}^{-1}\right)$ at 11:00 similarly, and there were more peak values which appeared at 13:00, 15:00 and 17:00 respectively in one day. In this research, the variation tendency of in the tillering stage and jointing stage was different from most graminaceous plants with a single peak (Philip et al., 1966; Yuan et al., 2009).

This study investigated its emergence reason and regulation. On one hand, the result is due to the strong nutritional growth of oat in the tillering stage and jointing stage. There are frequent matter and energy exchange with the environment in these two phases. On the other hand, it is related to the specific weather conditions (such as amounts of moisture in atmosphere vary greatly as a direct result of stronger solar radiation and frequent rainfall in a day) in Tibet alpine pasture.
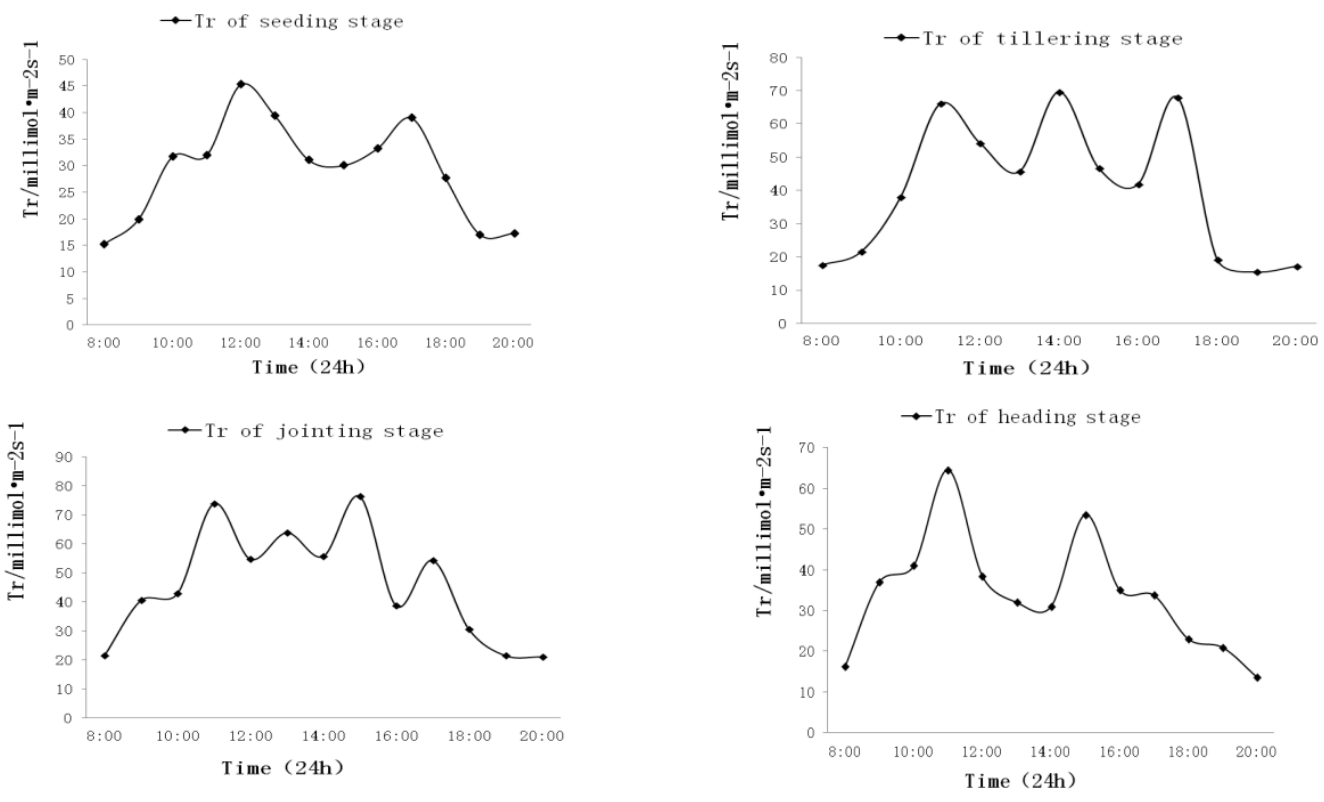

Figure 4. Daily variation of Tr under different growing periods 


\section{Relationships between physiological indexes of oat and single meteorological factor}

The daily variation relationships between $\psi_{L}, T r, P n$ and $T, R_{S}, R H$ were analyzed with SPSS and presented in Table 3. Results showed that the change trend of $\psi_{L}$ could be predicted simply by typical meteorological factors, as many studied reported that there were obvious relationships between the $T, R_{s}, R H$ and $\psi_{L}$ (Zhang et al., 2008). The correlation order of $T, R_{S}, R H$ with $\psi_{L}$ was: $T>R H>R_{s}$ with correlation coefficients of $0.728,0.676$ and 0.353 , respectively. From the models, the $\psi_{L}$ decreased by $1.96 \mathrm{Mpa}$ with the temperature increasing by $10^{\circ} \mathrm{C}$. Due to the $R_{s}$ was always positive number, the relationship between $\psi_{L}$ and $R_{s}$ was inversely proportional quadratic parabola trend. Different from the other two meteorological factors, the logarithmic relationship appeared between $\psi_{L}$ and $R H$.

Table 3. Regression model of single meteorological factors and crop physiological indexes

\begin{tabular}{c|c|c|c|c}
\hline $\begin{array}{c}\text { Crop physiology } \\
\text { index }\end{array}$ & $\begin{array}{c}\text { Meteorological } \\
\text { factor }\end{array}$ & Regression model & $\begin{array}{c}\text { Determinate } \\
\text { coefficient } \mathbf{R}^{2}\end{array}$ & F test value \\
\hline \multirow{3}{*}{$\psi_{L}(\mathrm{Mpa})$} & $R H$ & $\psi_{L}=-30.46+6.65 * \ln (\mathrm{RH})$ & $0.676^{* *}$ & 45.413 \\
& $R_{s}$ & $\psi_{L}=-2.066-0.647 \mathrm{R}_{s}-0.077 \mathrm{R}_{\mathrm{s}}{ }^{2}$ & $0.353^{*}$ & 4.523 \\
& $T$ & $\psi_{L}=-0.101-0.196 \mathrm{~T}$ & $0.728^{* *}$ & 58.578 \\
\hline & $R H$ & $T r=-43.544+2.481 \mathrm{RH}-0.021 \mathrm{RH}^{2}$ & $0.504^{*}$ & 5.584 \\
$\operatorname{Tr}\left(\mathrm{millimol} \cdot \mathrm{m}^{-2} \mathrm{~s}^{-1}\right)$ & $R_{s}$ & $T r=12.121 * \exp \left(0.2880 * \mathrm{R}_{\mathrm{s}}\right)$ & $0.360^{*}$ & 6.180 \\
& $T$ & $T r=-19.369+13.897 * \ln (\mathrm{T})$ & $0.328^{*}$ & 5.867 \\
\hline & $R H$ & $P \mathrm{n}=-43.465+2.198 * \mathrm{RH}-0.0002 * \mathrm{RH}^{3}$ & $0.529^{*}$ & 6.173 \\
$P \mathrm{n}\left(\mu \mathrm{mol} \cdot \mathrm{m}^{-2} \mathrm{~s}^{-1}\right)$ & $R_{s}$ & $P \mathrm{n}=28.165+8.008 \mathrm{R}_{\mathrm{s}}$ & $0.354^{*}$ & 3.041 \\
& $T$ & $P \mathrm{n}=12.947 * \mathrm{~T}^{0.392}$ & $0.538^{*}$ & 8.166 \\
\hline
\end{tabular}

"Correlation is significant at the 0.05 level

*** Correlation is significant at the 0.01 level

Number of samples for $\psi_{L}$ was $216(24 \times 9=216)$, number of samples for $\operatorname{Tr}$ was $48(12 \times 4=48)$ and number of samples for $P$ n was $48(12 \times 4=48)$

The $R_{s}$ guarantees the energy for crop transpiration. The crop transpiration rate $(T r)$ increases with the increase in water potential gradient, caused by stronger $R_{s}$, higher temperature and reduced atmospheric water. The correlation order between $\operatorname{Tr}$ and $T, R_{s}$, $R H$ was: $R H>R_{s}>T$ with correlation coefficient of $0.504,0.36$ and 0.328 , respectively. The relationship trend between $T r$ and $R H$ was the quadratic downward. The relationship between $T r$ and $R H$ was different from $\psi_{L}$ with the trend of inversely proportional quadratic parabola. The maximum $T r$ appeared when the $R H$ equaled to $59.07 \%$ and the $T r$ would decreased with $R H$ increasing when the $R H$ was greater than 59.07\%. Differently from others, the relationship trend between $\operatorname{Tr}$ and $R_{S}$ was exponential. The minimum $\operatorname{Tr}$ was 12.121 millimol $\bullet \mathrm{m}^{-2} \mathrm{~s}^{-1}$ while $R_{\mathrm{s}}$ was 0 . Logarithmic relationship was shown between $\operatorname{Tr}$ and $T$ and there was not transpiration when the temperature was less than $4.03{ }^{\circ} \mathrm{C}$. Then the transpiration rate will increase with the increase in temperature.

The impact factors on $P n$ of oat are not only the temperature but also the crop stomatal opening, transpiration changes and intercellular carbon dioxide concentration. 
Nevertheless, the $P n$ will affect the crop development. The correlation order between $P n$ and $T, R_{s}, R H$ was: $T>R H>R_{s}$ with correlation coefficient of $0.538,0.529$ and 0.354, respectively. Different from the $T r$, the relationship trend between $P n$ and $R H$ was the cubic polynomial. The linear relationship was presented between $P n$ and $R_{s}$. An $80.08 \mu \mathrm{mol} \cdot \mathrm{m}^{-2} \mathrm{~s}^{-1} \mathrm{Pn}$ increment appeared when the $R_{s}$ increased by $10 \mathrm{MJ} \mathrm{m}^{-2} \mathrm{~h}^{-1}$. The relationship trend between $P n$ and $T$ was different from others. Power function was showed between $P n$ and temperature with the power exponent of 0.392 .

Then the relationship between $\psi_{L}$ and physical signs will be introduced in great detail. If irrigation is sufficient, the change trend of $\psi_{L}$ is affected not only the different growth stages but also the meteorological factors. The change of $\psi_{L}$ can reflect the crop ability adapting to the environment.

With the uncertain meteorological condition, the data of $\psi_{L}$ and meteorological factors collected from August $7^{\text {th }}$ to August $12^{\text {th }}$ when the weather conditions and humidity were suitable for analysis, in order to eliminate the particular of observation data as much as possible in one day. The metrological and $\psi_{L}$ data observed over six days were averaged, which is an effective measure to reduce the error caused by the particular data.

(1) The diurnal variation relationship between $\psi_{L}$ and $R_{S}$

From the change curve (Fig. 5), the change trend about the $\psi_{L}$ and $R_{s}$ are negative correlation $\left(\mathrm{R}^{2}=0.353\right)$. The $R_{s}$ started to change from negative value to positive value at 5:00. It reached maximum $\left(3.45 \mathrm{MJ} \mathrm{m}^{-2} \mathrm{~h}^{-1}\right)$ at 12:00. However, the $\psi_{L}$ decreased rapidly from $-0.32 \mathrm{MPa}$ at 7:00, reached the first minimum at 13:00 and started to increase after two slight rebounds between 13:00-15:00. The fluctuation of $\psi_{L}$ may be impacted by other meteorological factors (Yang et al., 2012). From the above analysis, the changes of $\psi_{L}$ lagged behind the changes of $R_{S}$.

(2) The diurnal variation relationship between $\psi_{L}$ and $R H$

The change trend of $\psi_{L}$ and $R H$ are a positive correlation $\left(\mathrm{R}^{2}=0.676 ;\right.$ Fig. 5). After the sunrise, $R H$ tended to drop off over time with the maximum $87 \%$ at 8:00. The minimum appeared at 18:00 with $42.67 \%$. Both $\psi_{L}$ and $R H$ started to rise after the sunset and the $\psi_{L}$ reached to $-1.8 \mathrm{Mpa}$ in the end.

(3) The diurnal variation relationship between $\psi_{L}$ and $T$

The change trend of $\psi_{L}$ and $T$ are a negative correlation obviously $\left(\mathrm{R}^{2}=0.728\right)$ (Fig. 5). At daylight, the $\psi_{L}$ decreased while $T$ was rising, and $T$ reached to minimum of $3.15^{\circ} \mathrm{C}$ at 7:00, however $\psi_{L}$ was at a higher value with $-0.32 \mathrm{Mpa} . T$ tended to drop off after it reached the maximum value of $27.5^{\circ} \mathrm{C}$ at $15: 00$. In addition, the continuous high temperature would lead to $\psi_{L}$ picks up again with "nap".
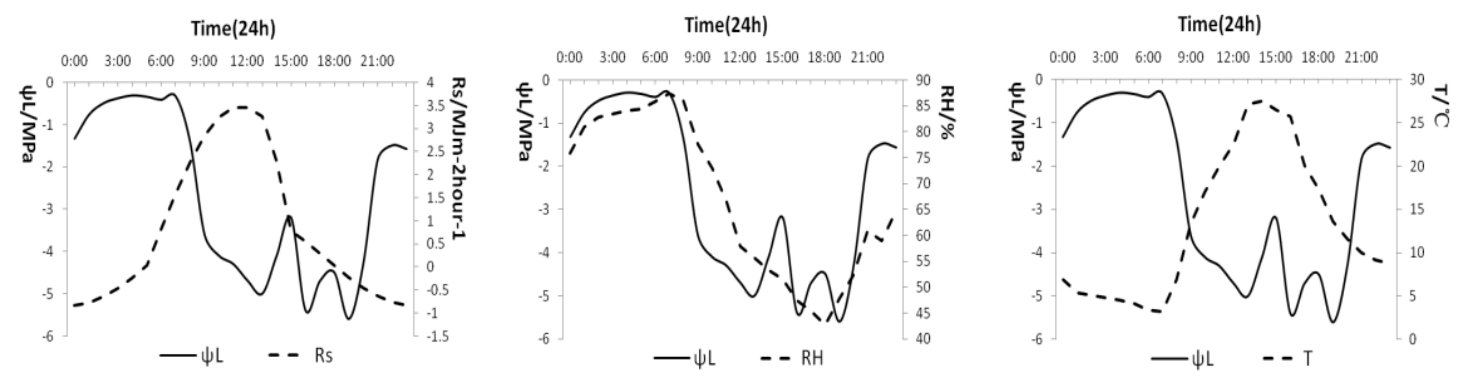

Figure 5. The relationship between daily variation of leaf water potential and meteorological factors 


\section{Relationships between physiological indexes of oat and comprehensive factors}

The crop physiological indicators are usually influenced by multiple meteorological factors comprehensively, such as temperature, humidity and so on. For example, the daily variation of $\psi_{L}$ is little on cloudy days with large humidity and wind speed, while the daily variation of $\psi_{L}$ is larger on sunny day with small wind speed and moderate humidity. By multiple regression analysis between the data of oat's physiological indexes and comprehensive factors, the $\psi_{L}, \operatorname{Tr}$ and $P_{n}$ of oat in alpine region can be predicted under condition of adequate water supply. The regression models between $\psi_{L}$ $T r, P n$ and meteorological factors are presented in Table 4. The correlation coefficients are $0.86,0.78$ and 0.66 , respectively.

Table 4. Regression model of multi-meteorological factors and crop physiological indexes

\begin{tabular}{c|c|c|c}
\hline Crop physiology index & Regression model & $\begin{array}{c}\text { Determinate } \\
\text { coefficient } \mathbf{R}^{2}\end{array}$ & F test value \\
\hline$\psi_{L}(\mathrm{Mpa})$ & $\psi_{L}=-11.271-0.882 \mathrm{R}_{\mathrm{s}}+0.076 \mathrm{~T}+0.123 \mathrm{RH}$ & $0.86^{* *}$ & 40.95 \\
$\operatorname{Tr}\left(\mathrm{millimol} \cdot \mathrm{m}^{-2} \mathrm{~s}^{-1}\right)$ & $\operatorname{Tr}=-39.375+1.606 \mathrm{~T}+0.453 \mathrm{RH}+0.056 \mathrm{R}_{\mathrm{s}}$ & $0.78^{*}$ & 11.90 \\
$P \mathrm{n}\left(\mu \mathrm{mol} \mathrm{m} \mathrm{s}^{-1}\right)$ & $P \mathrm{n}=-7.603+0.919 \mathrm{~T}+0.319 \mathrm{RH}+5.848 \mathrm{R}_{\mathrm{s}}$ & $0.66^{*}$ & 10.40 \\
\hline
\end{tabular}

*Correlation is significant at the 0.05 level

*** Correlation is significant at the 0.01 level

Number of samples for $\psi_{L}$ was $216(24 \times 9=216)$, number of samples for $\operatorname{Tr}$ was $48(12 \times 4=48)$ and number of samples for $P$ n was $48(12 \times 4=48)$

\section{Conclusions}

With the water resources becoming scarcer, the water-saving agriculture in Tibet plateau has drawn much attention. At the same time, the oat physiological indexes research is indispensable for water-saving agriculture. The results show that the daily oat's $\psi_{L}$ changed obviously during the different growth stages. The daily change curve of oat's $\psi_{L}$ showed 'V-type' in the seeding and heading stages, and the lowest value appeared at 5:00 and 16:00 respectively. However, oat's $\psi_{L}$ showed 'W-type' in the jointing and tillering stages in which the lowest value both appeared in the morning and afternoon. The maximum change range of $\psi_{L}$ can reach to $6 \mathrm{MPa}$ in a day.

The variation tendency of oat's $P n$ was basically consistent without fixed peaks and troughs model in different growth stages. As the facts mentioned above, $P n$ presented a decreasing tendency in a day. The $P n$ on the morning was higher than that on the afternoon and the peak appeared between 9:00 and 10:00 at one day. The maximum of $P n$ in the seeding stage, tillering stage, jointing stage and heading stage were 10.56, 9.91, 10.01 and $9.01 \mu \mathrm{mol} \mathrm{m} \mathrm{m}^{-1}$, respectively.

The $\operatorname{Tr}$ of oat at the seeding stage was obviously less than that in the tillering stage, jointing stage and heading stage. The $T r$ presented double-peak curves and midday depression in the seeding and heading stage. Different from the current research about grass, the variation tendency about $\operatorname{Tr}$ of oat in the tillering stage and jointing stage was "Multi-peak" type without distinct midday depression and parabolic tendency.

Based on the regression analysis, the correlation coefficients between meteorological factors and oat's four physiological indicators were: $T>R H>R_{S} ; R H>R_{S}>T$; $T>R H>R_{s}$, respectively for $\psi_{L}, \operatorname{Tr}$ and $P n$. By multiple regression analysis between the data of oat's physiological indexes and comprehensive factors, the $\psi_{L}, \operatorname{Tr}$ and $P n$ of 
oat in alpine region can be predicted under condition of adequate water supply. These results are useful to understand the hydrologic cycle of the irrigated grass and determine the scientific irrigation schedule to improve water use efficiency of grass in the alpine area.

The studies about $\psi_{L}, T r$ and $P n$ in this paper are under the condition of full irrigation. Therefore, in order to determine the scientific irrigation schedule, the influence of water stress on $\psi_{L}, \operatorname{Tr}$ and $P n$ will be the focus of the further study.

Acknowledgements. This research was supported by China Institute of Water Resources and Hydropower Research (MK2017J02), National Natural Science Foundation of China (51579158, 51609154), State Key Laboratory of Simulation and Regulation of Water Cycle in River Basin (SKL2018ZY01). The contributions of the editor and anonymous reviewers whose comments and suggestions significantly improved this article are also appreciated.

\section{REFERENCES}

[1] Allen, R. G., Pereira, L. S., Raes, D., Smith, M. (1998): Crop evapotranspiration guidelines for computing crop water requirements. - FAO Irrigation and Drainage Paper 56: $18-38$.

[2] Ball, J. T., Woodrow, I. E., Berry, J. A. (1987): A Model Predicting Stomatal Conductance and Its Contribution to the Control of Photosynthesis under Different Environmental Conditions. - In: Biggins, J., Nijhoff, M. (eds.) Progress in Photosynthesis Research, pp. 221-224. Nijhoff, Dordrecht.

[3] Cowan, I. R., Farquhar, G. D. (1977): Stomatal function in relation to leaf metabolism and environment. - Sympopsia Society for Experimental Biology 31: 471-505.

[4] Dwelle, R. B., Hurley, P. J., Pavek, J. J. (1983): Photosynthesis and stomatal conductance of potato clones (Solanum tuberosum L.). - Plant Physiol. 72: 172-176.

[5] Farquhar, G. D., Sharkey, T. D. (1982): Stomatal conductance and photosynthesis. Annual Review of Plant Physiology 33: 317-345.

[6] Fu, A. H., Chen, Y. N., Li, W. H. (2012): Analysis on dominant factors influencing water potential of Phragmites australis in extremely arid areas. - Acta Prataculturae Sinica 21: 163-170.

[7] Guo, K. Z., Tong, C. F., Hao, H. P., Yang, Y. S., Xu, B. (2006): Research on water consuming process in alfalfa in Maowusu Desert. - Journal of Irrigation and Drainage 6: 44-48.

[8] Han, L., He, K. N., Lu, X. J. (2008): Changes and environmental effects of leaf water potential of Caryopteris mongolica in Qinghai alpine semi-arid area. - Bulletin of Soil and Water Conservation 6: 1-5.

[9] Jarvis, P. (1976): The interpretation of the variations in leaf water potential and stomatal conductance found in canopies in the field. - Philosophical Transactions of the Royal Society of London B, Biological Sciences 273: 593-610.

[10] Johnson, J. D., Ferrell, W. K. (1983): Stomatal response to vapour pressure deficit and the effect of plant water stress. - Plant Cell Environment 6: 451-456.

[11] Kang, S. Z., Liu, X. M., Wang, Z. Y. (1991): Relations between leaf water potential, stomatal resistance and transpiration rate of winter wheat, and environmental factors. Journal of Irrigation and Drainage 3: 1-6.

[12] Kang, S. Z., Liu, X. M., Xiong, Y. Z. (1994): Theory of Water Transmission and Its Application in the Soil-Plant-Atmosphere Continuum Body. - Hydraulic and Power Press, Beijing (in Chinese). 
[13] Ku, S. B., Edwards, G. E., Tanner, C. B. (1977): Effects of light, carbon dioxide and temperature on photosynthesis, oxygen inhibition of photosynthesis, and transpiration in Solanum tuberosum. - Plant Physiol. 59: 868-872.

[14] Leuning, R. (1995): Acritical appraisal of a combined stomatal-photosynthesis model for $\mathrm{C}_{3}$ plants. - PlantCell Environ 18: 339-355.

[15] Li, B., Huang, Y. T., Huang, Y. F., Gong, H. G. (2013): Effect of shades on diurnal variation of photosynthesis parameters of Camellia japonica 'Liexiang'. - Forestry Science and Technology of Guangdong Province 29: 49-53.

[16] Li, W. M., Zhou, L. Y. (2004): Physiolycial and ecological responses of wheat leaves to soil water and nitrogen (I) effects of soil water and nitrogen on wheat photosynthesis and water use efficiency. - Chinese Journal of Soil Science 35(2): 136-142.

[17] Liu, J., Li, F. X., Wang, L. X., Zhang, X. Y., Dai, X. L., Su, Z. S. (2003): Effect of irrigation on transpiration rate of spring wheat and its causation. - Journal of Triticeae 23(1): 58-62.

[18] Liu, J. H., Zhao, H. C., Ren, Y. F., Zhang, X. Q., Wang, Y. (2009): Change of osmotica leaf under soil moisture stress. - Acta Botanica Boreali-Occidentalia Sinica 29: 14321436.

[19] Liu, Y. H., Jia, Z. K., Shi, J. A., Han, Q. F. (2006): Daily dynamics of photosynthesis in alfalfa varieties under dry farming conditions. - Acta Ecologica Sinica 26: 1469-1476.

[20] Luo, Y. Z., Cheng, Z. Y. (2011): Impact of water stress on leaf water potential, transpiration rate (Tr) and stomatal conductance (Gs) of alfalfa. - Acta Agrestia Sinica 19: $215-221$.

[21] Medlyn, B. E., Duursma, R. A., Eamus, D., Ellsworth, D. S., Prentice, I. C., Barton, C. V. (2011): Reconciling the optimal and empirical approaches to modelling stomatal conductance. - Global Change Biology 17: 2134-2144.

[22] Moorby, J., Munns, R., Walcott, J. (1975): Effects of water deficit on photosynthesis and tuber metabolism in potatoes. - Aust J Plant Physiol 2: 323-333.

[23] Peng, S. Z., Ding, J. L., Xu, J. Z., Liu, F. L. (2005): Experimentation of transpiration rate and influence factors of late rice. - Water Saving Irrigation 1: 1-4.

[24] Philip, J. R. (1966): Plant water relations: some physical aspects. - Ann. Rev. Plant Physiol. 17: 245-268.

[25] Sobrado, M. A. (1994): Leaf age effects on photosynthetic rate, transpiration rate and nitrogen content in a tropical dry forest. - Physiologia Plantarum 90: 210-215.

[26] Tamang, B. G., Sadok, W. (2018): Nightly business: Links between daytime canopy conductance, nocturnal transpiration and its circadian control illuminate physiological trade-offs in maize. - Environmental and Experimental Botany 148: 192-202.

[27] Tian, D. L., Xu, B., Guo, K. Z. (2012): Tibet alpine pastoral areas (oats and barley) crop water model sure. - China Rural Water and Hydropower 0: 9-12.

[28] Tong, C. F., Guo, K. Z., Shi, H. B. (2005): Preliminary study on the effect of environmental factor on leaf potential and transpiration rate of alfalfa. - Transactions of the Chinese Society of Agricultural Engineering 12: 152-155.

[29] Wan, S. M., Jia, Z. K., Yang, B. P. (2009): Relationship between diurnal changes of alfalfa net photosynthetic rate and environmental factors. - Acta Agrestia Sinica 17: 2731.

[30] Wardlaw, I. F. (1967): The effect of water on stress on translocation in relation to photosynthesis and growth I. Effect during grain development in wheat. - Aust. J. Biol. Sci. 1967(20): 25-39.

[31] Yang, P. L., Peng, J., Zhong, X. C. (2012): Study on the leaf, stalk and soil water potential of the tree species of protection forest under different water treatments. Xinjiang Agricultural Sciences 49: 273-278.

[32] Yao, S. M., Kang, Y. H., Liu, H. J. (2009): Diurnal change and influencing factors of winter wheat's leaf water potential during grain filling stage under sprinkler irrigation condition. - Agricultural Research in the Arid Areas 27: 1-6. 
[33] Yu, W. Y., Ji, R. P., Feng, R., Zhao, X. L., Zhang, Y. S. (2015): Response of water stress on photosynthetic characteristics and water use efficiency of maize leaves in different growth stage. - Acta Ecologica Sinica 35(9): 2902-2909.

[34] Yuan, S. F., Tang, H. P. (2009): Daily dynamics of gas exchange characteristics of three ephemeral plants in Dzungaria Desert. - Acta Ecologica Sinica 29: 1962-1970.

[35] Zhang, M., Zhang, R. Z., Cai, L. Q. (2008): Leaf water potential of spring wheat and field pea under different tillage patterns and its relationships with environmental factors. Chinese Journal of Applied Ecology 19: 1467-1474.

[36] Zhao, F. H., Wang, Q. F., Wang, J. L., Wang, J. S., Ouyang, Z., Yu, R. (2011): Photosynthesis-transpiration coupling mechanism of wheat and maize during daily variation. - Acta Ecologica Sinica 31(24): 7526-7532. 